\title{
PENGARUH KANDUNGAN ETHANOL PADA BENSIN TERHADAP KONSUMSI BAHAN BAKAR SEPEDA MOTOR EFI 115 CC DAN 125 CC BERTRANSMISI CVT
}

\author{
Tabah Priangkoso*, Aghus Nailul Irsyad dan Imam Wahminto \\ Jurusan Teknik Mesin, Fakultas Teknik, Universitas Wahid Hasyim \\ Jl. Menoreh Tengah X/22, Sampangan Semarang 50236 \\ *Email: tabah@unwahas.ac.id
}

\begin{abstract}
Abstrak
Ethanol mulai digunakan sebagai bahan bakar substitusi bensin sebagai bahan bakar mesin pembakaran dalam. Penelitian ini bertujuan untuk menguji pengaruh kandungan ethanol dalam bensin. Bensin yang digunakan diberikan ethanol 8\%, 10\%, dan 12\% v/v. Pengujian dilakukan menggunakan sepeda motor 4 langkah bertransmisi CVT masing-masing berkapasitas 115 cc dan 125 cc. Sepeda motor diuji di atas chassis dynamometer untuk mensimulasi hambatan yang dialami sepeda motor ketika melaju di jalan aspal. Pengujian dilakukan pada kecepatan $10 \mathrm{~km} / j$, $20 \mathrm{~km} / \mathrm{j}, 30 \mathrm{~km} / \mathrm{j}, 40 \mathrm{~km} / \mathrm{j}$, dan $50 \mathrm{~km} / \mathrm{j}$. Hasil pengujian menunjukkan bahwa ethanol meningkatkan jarak tempuh untuk semua jenis bensin dan semua kandungan ethanol. Peningkatan jarak tempuh tertinggi diperoleh untuk kandungan ethanol 10\% dibanding tanpa ethanol.
\end{abstract}

Kata kunci: ethanol, jarak tempuh, konsumsi bahan bakar.

\section{PENDAHULUAN}

Etanol mulai digunakan sebagai substitusi bensin (gasoline/petrol) untuk sumber energi mesin pembakaran dalam. Salah satu alasan penggunaan etanol dalam bensin adalah memperbaiki kualitas emisi gas buang dan meningkatkan kinerja mesin.

Etanol dihasilkan dari fermentasi glukosa yang diperoleh dari jagung, tebu, atau umbiumbian dan sejenisnya. Beberapa negara telah menggunakan etanol sebagai campuran bensin untuk mengurangi impor minyak. India, misalnya, telah membuat program untuk meningkatkan kandungan etanol pada bensin hingga 20\% (Saini, et al. 2010). Brasil juga membuat kebijakan yang sama untuk meningkatkan kandungan etanol dalam bensin hingga $27,5 \%$, sedangkan Indonesia belum menetapkan penggunaan etanol sebagai pengganti bensin dengan alasan lebih mahal dari pada bahan bakar fosil. Namun demikian, semakin terbatas dan mahalnya harga bahan bakar minyak fosil, harus diantisipasi dengan cara mencari penggantinya.

Salah satu faktor penting bagi pengguna kendaraan bermotor adalah konsumsi bahan bakar kendaraan. Laju konsumsi bahan bakar ini secara garis besar dipengaruhi empat faktor yaitu kendaraan, lingkungan, pengemudi, dan kondisi lalu lintas. Variabel utama dalam lalu lintas meliputi kecepatan, jumlah berhenti, dan percepatan. Faktor lingkungan pengendaraan yang dapat mempengaruhi konsumsi bahan bakar adalah kemiringan jalan, kondisi angin, temperatur lingkungan, ketinggian, jenis permukaan jalan (misalnya aspal, tanah, paving block), dan kondisi permukaan jalan (kekasaran, basah, kering) (Priangkoso et.al. 2016).

Penelitian ini bertujuan untuk mengetahui pengaruh kandungan etanol $\mathrm{v} / \mathrm{v}$ terhadap konsumsi bahan bakar minyak produksi PT Pertamina, yaitu Premium, Pertalite, Pertamax 93, dan Pertamax Turbo yang digunakan oleh sepeda motor.

Pengujian dilakukan menggunakan sepeda motor skuter bermesin 4 langkah dengan sistem suplai bahan bakar EFI bertransmisi CVT. Sepeda motor jenis ini dipilih sebagai alat uji mengingat jumlahnya yang sangat banyak di Indonesia.

\section{METODE}

Metode yang digunakan dalam penelitian ini adalah menyimulasi perjalanan sepeda motor di jalan beraspal dengan berbagai kecepatan. Simulasi dilakukan dengan menempatkan sepeda motor di atas chasis Dynamometer. Konsumsi bahan bakar diukur menggunakan buret dimana bahan bakar disuplai ke injektor.

Chassis dynamometer digunakan untuk memberi beban terhadap sepeda motor sesuai dengan beban yang dialami sepeda motor saat melaju di jalan aspal. Beban-beban yang dialami sepeda motor adalah hambatan aerodinamika 
yang meningkat sesuai dengan peningkatan kecepatan dan tahanan gelinding roda terhadap permukaan jalan beraspal. Kecepatan sepeda motor diukur berdasarkan kecepatan putar rol yang memberi beban roda belakang sebagai penggerak sepeda motor.

Asumsi yang digunakan dalam simulasi ini adalah udara dalam keadaan diam sehingga efek hambatan aerodinamis hanya terjadi karena gerak sepeda motor, temperatur dan kelembaban udara tidak berubah, dan kondisi jalan mulus tidak berlubang.

Hambatan aerodinamika dihitung menggunakan persamaan

$$
F_{a}=\frac{1}{2} \rho A v^{2}
$$

dimana

$\rho=$ kerapatan udara, $1,2 \mathrm{~kg} / \mathrm{m}^{3}$

$A=$ luas muka terkena hambatan, $\mathrm{m}^{2}$

$v=$ kecepatan aliran udara, $\mathrm{m} / \mathrm{s}$

Tahanan gelinding dihitung menggunakan persamaan

$$
\begin{aligned}
F r=(0,0136 & +0,4 \times 10^{-7} \\
\times & \left.v_{r}\right) \mathrm{mg}
\end{aligned}
$$

dimana

$v_{r}=$ kecepatan tangensial roda, $\mathrm{m} / \mathrm{s}$

$m=$ massa sepeda motor dan pengendara, $\mathrm{kg}$

$g=$ percepatan gravitasi bumi, $9,8 \mathrm{~m} / \mathrm{s}^{2}$ motor

Tahanan total yang dialami oleh sepeda

$$
F=F_{a}+F_{r}
$$

Dinamometer diatur untuk memberi beban sesuai dengan tahanan total $F$. Sepeda motor yang digunakan sebanyak 2 unit skuter bermesin 4 langkah, bertransmisi CVT, masing-masing berkapasitas $115 \mathrm{cc}$ dan 125 cc dengan sistem suplai bahan bakar EFI. Setting mesin sepeda motor sesuai dengan setting bengkel resmi ATPM dan tidak dilakukan perubahan meskipun jenis bensin diganti.

Konsumsi bahan bakar dihitung berdasarkan waktu yang diperlukan untuk menghabiskan bensin sebanyak $5 \mathrm{ml}$ untuk kecepatan $10 \mathrm{~km} / \mathrm{j}, 20 \mathrm{~km} / \mathrm{j}, 30 \mathrm{~km} / \mathrm{j}, 40 \mathrm{~km} / \mathrm{j}$, dan $50 \mathrm{~km} / \mathrm{j}$ untuk setiap jenis bensin dan setiap kandungan etanol 8\%, 10\%, dan $12 \%$ v/v. Sebagai kontrol pengaruh kandungan etanol terhadap konsumsi bahan bakar, ikut diuji bensin tanpa etanol atau kandungan $0 \%$ etanol.

Etanol yang digunakan sebagai campuran bahan bakar merupakan bioethanol dengan kandungan air $1 \%$ atau kurang. Konsumsi bahan bakar dihitung menggunakan persamaan

$$
K=\frac{v_{r}}{V}
$$

dimana

$v_{r}=$ kecepatan tangensial roda, $\mathrm{km} / \mathrm{s}$

$V=$ laju volume bensin, $\mathrm{L} / \mathrm{s}$

\section{HASIL DAN PEMBAHASAN}

Dengan memperhatikan Tabel 1 sampai dengan 4 dan Gambar 1 sampai dengan Gambar 4 dapat dilihat bahwa kandungan etanol dalam bensin meningkatkan efisiensi bahan bakar sepeda motor $115 \mathrm{cc}$. Hal ini ditunjukkan dengan jarak tempuh yang lebih jauh ketika menggunakan campuran etanol dibanding bensin murni.

Tabel 1 Konsumsi bahan bakar Premium dengan kandungan ethanol $0 \%, 8 \%, 10 \%$, $12 \%$ sepeda motor $115 \mathrm{cc}$ dalam $\mathrm{km} / \mathrm{L}$.

\begin{tabular}{crrrr}
\hline Kecepata $\begin{array}{c}\mathbf{n} \\
(\mathbf{k m} / \mathbf{j})\end{array}$ & \multicolumn{4}{c}{ Kandungan etanol v/v } \\
\cline { 2 - 5 } & $\mathbf{0 \%}$ & $\mathbf{8 \%}$ & $\mathbf{1 0 \%}$ & $\mathbf{1 2 \%}$ \\
\hline 10 & 5.17 & 5.11 & 11.06 & 6.56 \\
20 & 9.87 & 13.50 & 22.35 & 13.73 \\
30 & 12.82 & 16.22 & 30.67 & 19.38 \\
40 & 14.76 & 24.29 & 33.82 & 26.00 \\
50 & 22.76 & 31.15 & 45.31 & 31.70 \\
\hline
\end{tabular}

Tabel 2 Konsumsi bahan bakar Pertalite dengan kandungan ethanol $0 \%, 8 \%, 10 \%$, $12 \%$ sepeda motor $115 \mathrm{cc}$ dalam $\mathrm{km} / \mathrm{L}$

\begin{tabular}{crrrr}
\hline Kecepata & \multicolumn{4}{c}{ Kandungan ethanol v/v } \\
\cline { 2 - 5 } $\begin{array}{c}\mathbf{n} \\
(\mathbf{k m} / \mathbf{j})\end{array}$ & $\mathbf{0 \%}$ & $\mathbf{8 \%}$ & $\mathbf{1 0 \%}$ & $\mathbf{1 2 \%}$ \\
\hline 10 & 6.16 & 6.49 & 12.16 & 11.21 \\
20 & 12.00 & 16.87 & 21.54 & 16.79 \\
30 & 16.32 & 21.74 & 32.33 & 30.28 \\
40 & 17.66 & 26.80 & 43.48 & 38.86 \\
50 & 23.50 & 28.26 & 46.49 & 43.54 \\
\hline
\end{tabular}

Pada semua jenis bensin produk PT Pertamina, jarak tempuh meningkat hingga kandungan etanol $10 \%$, kemudian menurun pada kandungan etanol $12 \%$. Dengan demikian, secara umum kandungan etanol $10 \%$ memberikan hasil terbaik dalam meningkatkan 
efisiensi dengan melihat jarak tempuhnya yang paling jauh untuk semua kecepatan dan untuk semua jenis bensin.

Tabel 3 Konsumsi bahan bakar Pertamax 92 dengan kandungan ethanol $0 \%, 8 \%, 10 \%$, $12 \%$ sepeda motor $115 \mathrm{cc}$ dalam $\mathrm{km} / \mathrm{L}$

\begin{tabular}{crrrr}
\hline \multirow{2}{*}{$\begin{array}{c}\text { Kecepatan } \\
(\mathbf{k m} / \mathbf{j})\end{array}$} & \multicolumn{4}{c}{ Kandungan etanol v/v } \\
\cline { 2 - 5 } & $\mathbf{0 \%}$ & $\mathbf{8 \%}$ & $\mathbf{1 0 \%}$ & $\mathbf{1 2 \%}$ \\
\hline 10 & 5.93 & 6.08 & 8.64 & 7.88 \\
20 & 9.38 & 15.77 & 18.19 & 16.34 \\
30 & 11.68 & 21.23 & 25.26 & 23.03 \\
40 & 15.87 & 32.65 & 34.82 & 26.41 \\
50 & 15.28 & 35.86 & 43.10 & 41.19 \\
\hline
\end{tabular}

Hasil pengujian konsumsi bahan bakar sepeda motor berkapasitas 115 cc menggunakan bensin Premium, Pertalite, Pertamax 92, dan Pertamax Turbo disajikan pada Tabel 1 sampai dengan Tabel 5 dan Gambar 1 sampai dengan Gambar 5.

Tabel 4 Konsumsi bahan bakar Pertamax Turbo dengan kandungan ethanol $0 \%, 8 \%$, $10 \%, 12 \%$ sepeda motor 115 cc dalam $\mathrm{km} / \mathrm{L}$

\begin{tabular}{crrrr}
\hline $\begin{array}{c}\text { Kecepata } \\
\mathbf{n}\end{array}$ & \multicolumn{4}{c}{ Kandungan etanol v/v } \\
\cline { 2 - 5 } $\mathbf{j})$ & $\mathbf{0 \%}$ & $\mathbf{8 \%}$ & $\mathbf{1 0 \%}$ & $\mathbf{1 2 \%}$ \\
\hline 10 & 5.10 & 5.72 & 6.70 & 6.80 \\
20 & 8.87 & 13.12 & 17.74 & 12.99 \\
30 & 10.65 & 15.52 & 23.58 & 19.36 \\
40 & 13.40 & 17.60 & 28.33 & 23.69 \\
50 & 16.18 & 18.74 & 30.38 & 28.44 \\
\hline
\end{tabular}

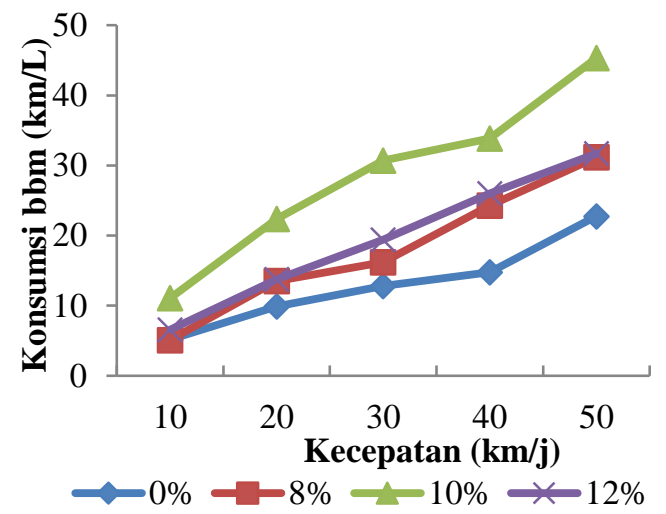

Gambar 1 Konsumsi bahan bakar sepeda motor 115 cc menggunakan Premium

Hasil pengujian konsumsi bahan bakar sepeda motor berkapasitas $115 \mathrm{cc}$ menggunakan bensin Premium, Pertalite, Pertamax 92, dan Pertamax Turbo disajikan pada Tabel 1 sampai dengan Tabel 5 dan Gambar 1 sampai dengan Gambar 5

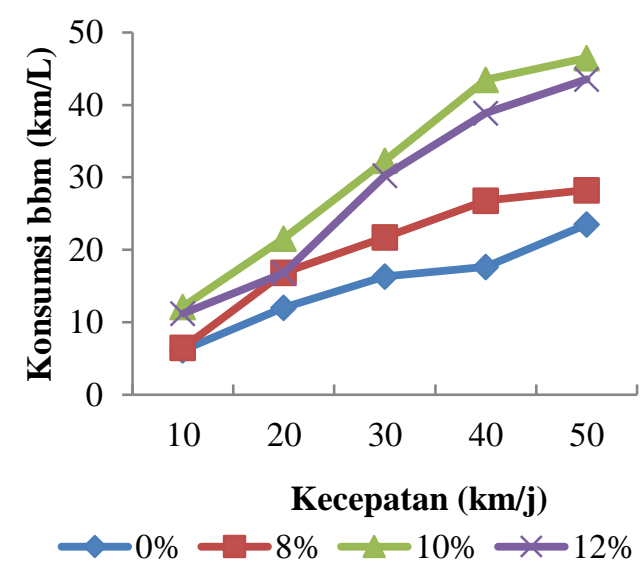

Gambar 2 Konsumsi bahan bakar sepeda motor 115 cc menggunakan Pertalite

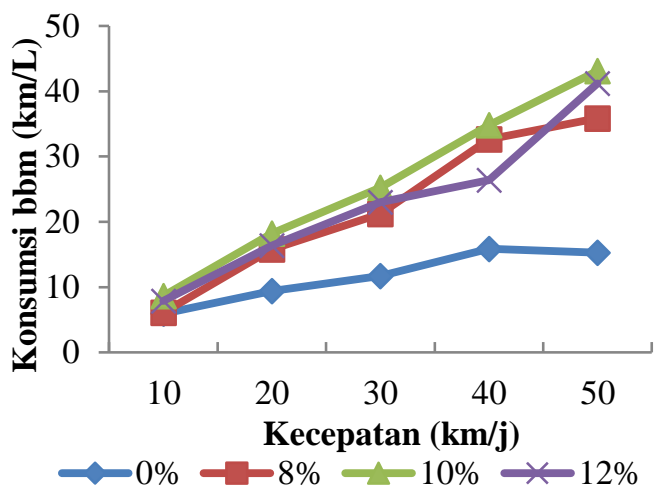

Gambar 3 Konsumsi bahan bakar sepeda motor 115 cc menggunakan Pertamax 92

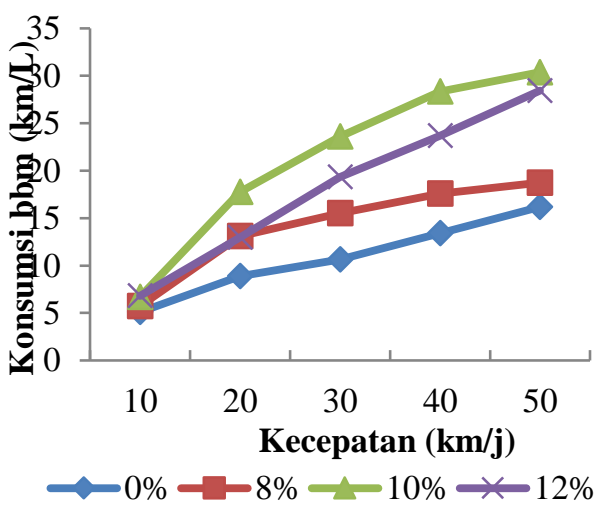

Gambar 4 Konsumsi bahan bakar sepeda motor 115 cc menggunakan Pertamax Turbo

Sedangkan hasil pengujian konsumsi bahan bakar sepeda motor berkapasitas $125 \mathrm{cc}$ 
disajikan pada Tabel 6 sampai dengan Tabel 9 dan Gambar 6 sampai dengan Gambar 9.

Tabel 5 Peningkatan jarak tempuh untuk kandungan ethanol $10 \%$ dalam bensin menggunakan sepeda motor $115 \mathrm{cc}$, dalam \%

\begin{tabular}{ccccc}
$\begin{array}{c}\text { Kec } \\
(\mathbf{k m} / \mathbf{j})\end{array}$ & Premium & Pertalite & $\begin{array}{c}\text { Pertamax } \\
\mathbf{9 2}\end{array}$ & $\begin{array}{c}\text { Pertamax } \\
\text { Turbo }\end{array}$ \\
\hline 10 & 114 & 97 & 46 & 31 \\
20 & 126 & 80 & 94 & 100 \\
30 & 139 & 98 & 116 & 121 \\
40 & 129 & 146 & 119 & 111 \\
50 & 99 & 98 & 182 & 88 \\
\hline
\end{tabular}

Sedangkan efek kandungan etanol terhadap peningkatan jarak tempuh sepeda motor diperlihatkan pada Tabel 5 dan Gambar 5 untuk sepeda motor $115 \mathrm{cc}$ dan Tabel 10 dan Gambar 10 untuk sepeda motor $125 \mathrm{cc}$ pada Tabel 5 dan Gambar 5.

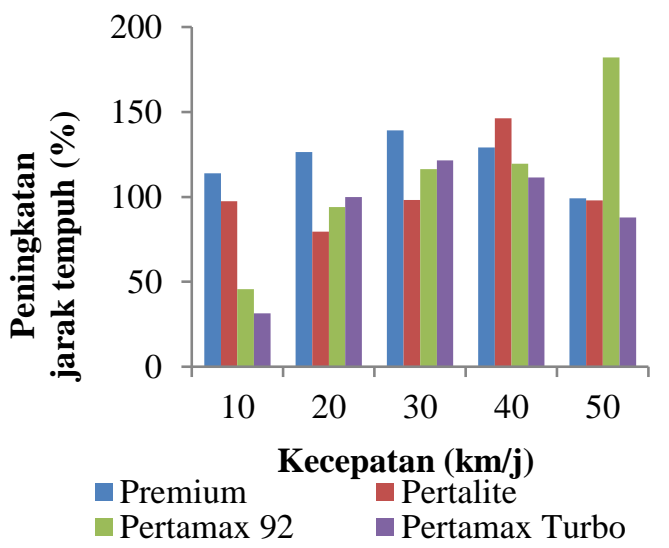

Gambar 5 Peningkatan jarak tempuh untuk kandungan ethanol $10 \%$ menggunakan sepeda motor 115 cc

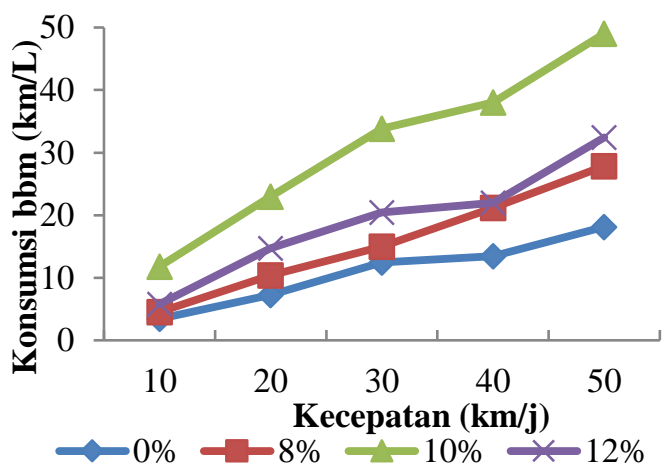

Gambar 6 Konsumsi bahan bakar sepeda motor 125 cc menggunakan Premium

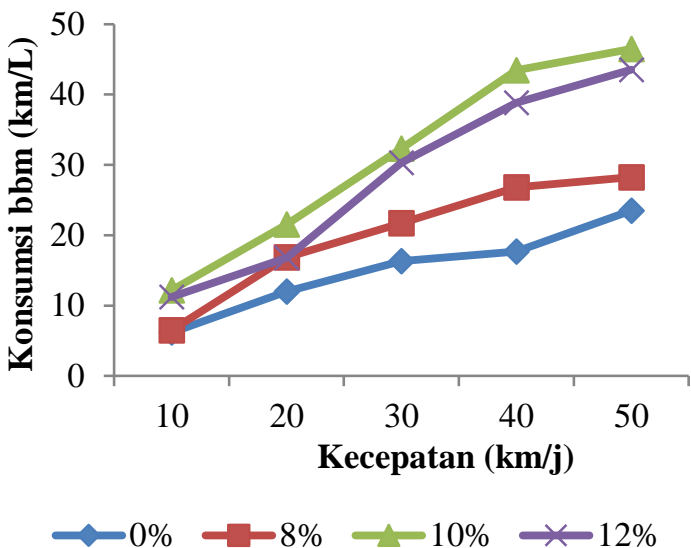

Gambar 7 Konsumsi bahan bakar sepeda motor 125 cc menggunakan Pertalite

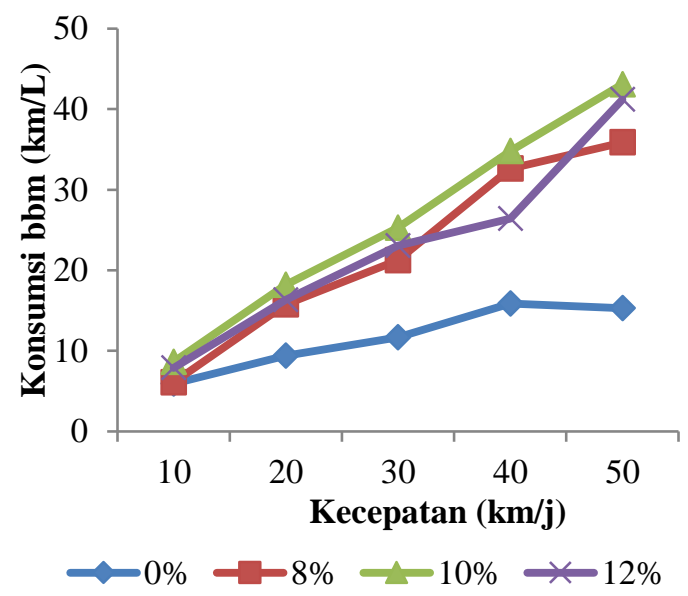

Gambar 8 Konsumsi bahan bakar sepeda motor 125 cc menggunakan Pertamax 92

Kandungan etanol 10\% memberikan hasil terbaik pada penggunaan Premium pada kecepatan $30 \mathrm{~km} / \mathrm{j}$ sebesar 139\%, Pertalite pada kecepatan $40 \mathrm{~km} / \mathrm{j}$ sebesar 146\%, Pertamax 92 pada kecepatan $50 \mathrm{~km} / \mathrm{j}$ sebesar $182 \%$, dan Pertamax Turbo sebesar $121 \%$ pada kecepatan $30 \mathrm{~km} / \mathrm{j}$ dibanding penggunaan bensin tanpa etanol. Peningkatan jarak tempuh dapat dilihat pada tabel 6 sampai dengan Tabel 9 dan Gambar 6 sampai dengan 9, fenomena yang dihasilkan akibat kandungan etanol pada sepeda motor 125 cc mirip dengan yang terjadi pada sepeda motor 115 cc, yaitu kandungan etanol 10\% dalam bensin memberikan jarak tempuh terjauh dibanding tanpa etanol maupun kandungan $8 \%$ dan $12 \%$. 


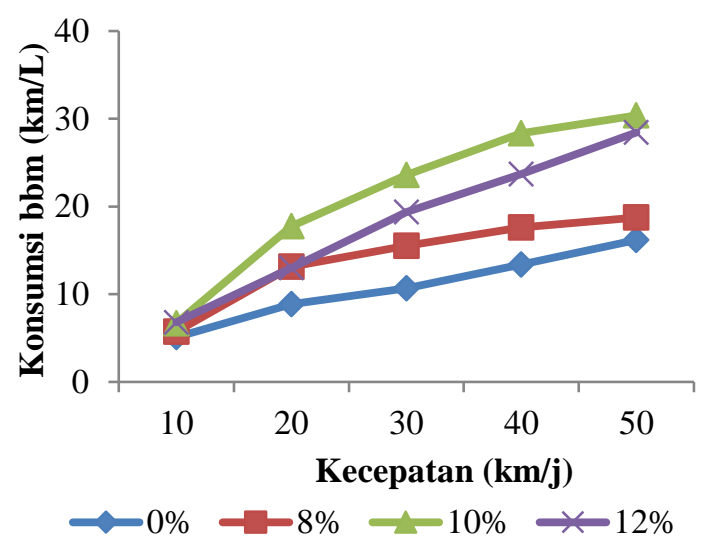

Gambar 9 Konsumsi bahan bakar sepeda motor 125 cc menggunakan Pertamax Turbo

Tabel 6 Konsumsi bahan bakar Premium dengan kandungan ethanol $0 \%, 8 \%, 10 \%$, $12 \%$ sepeda motor $125 \mathrm{cc}$ dalam $\mathrm{km} / \mathrm{L}$

\begin{tabular}{crrrr}
\hline $\begin{array}{c}\text { Kecepatan } \\
(\mathbf{k m} / \mathbf{j}))\end{array}$ & \multicolumn{4}{c}{ Kandungan etanol v/v } \\
\cline { 2 - 5 } & $0 \%$ & $\mathbf{8 \%}$ & $\mathbf{1 0 \%}$ & $\mathbf{1 2 \%}$ \\
\hline 10 & 3.44 & 4.53 & 11.81 & 5.79 \\
20 & 7.25 & 10.37 & 22.98 & 14.69 \\
30 & 12.44 & 15.01 & 33.84 & 20.45 \\
40 & 13.47 & 21.16 & 38.01 & 21.98 \\
50 & 18.14 & 27.86 & 49.02 & 32.43 \\
\hline
\end{tabular}

Tabel 7 Konsumsi bahan bakar Pertalite dengan kandungan ethanol $0 \%, 8 \%, 10 \%$, $12 \%$ sepeda motor $125 \mathrm{cc}$ dalam $\mathrm{km} / \mathrm{L}$

\begin{tabular}{ccccc}
\hline \multirow{2}{*}{$\begin{array}{c}\text { Kec } \\
\mathbf{k m} / \mathbf{j})\end{array}$} & \multicolumn{4}{c}{ Kandungan etanol v/v } \\
\hline 10 & 5.30 & $\mathbf{8 \%}$ & $\mathbf{1 0 \%}$ & $\mathbf{1 2 \%}$ \\
20 & 10.08 & 11.48 & 12.39 & 7.95 \\
30 & 16.04 & 16.21 & 34.21 & 16.20 \\
40 & 21.86 & 21.96 & 43.74 & 29.97 \\
50 & 23.38 & 29.65 & 55.08 & 35.75 \\
\hline
\end{tabular}

Tabel 8 Konsumsi bahan bakar Pertamax 92 dengan kandungan ethanol $0 \%, 8 \%, 10 \%$, $12 \%$ sepeda motor $125 \mathrm{cc}$ dalam $\mathrm{km} / \mathrm{L}$

\begin{tabular}{crrrr}
\hline Kec & \multicolumn{5}{c}{ Kandungan etanol v/v } \\
\cline { 2 - 5 }$(\mathbf{k m} / \mathbf{j})$ & $\mathbf{0 \%}$ & $\mathbf{8 \%}$ & $\mathbf{1 0 \%}$ & $\mathbf{1 2 \%}$ \\
\hline 10 & 5.71 & 5.34 & 11.97 & 6.67 \\
20 & 10.98 & 9.88 & 23.06 & 15.46 \\
30 & 13.32 & 16.11 & 32.67 & 22.21 \\
40 & 17.21 & 21.62 & 43.57 & 28.02 \\
50 & 19.93 & 23.89 & 49.15 & 33.21 \\
\hline
\end{tabular}

Efek terbaik bagi peningkatan jarak tempuh untuk sepeda motor $125 \mathrm{cc}$ terjadi pada penggunaan Premium dengan etanol 10\% sebesar $243 \%$ dibanding tanpa etanol pada kecepatan $10 \mathrm{~km} / \mathrm{j}$, dan kemudian menurun pada kecepatan-kecepatan yang lebih besar. Untuk Pertalite, efek terbesar terjadi pada kecepatan 50 $\mathrm{km} / \mathrm{j}$ dengan peningkatan jarak tempuh mencapai 136\% dibanding tanpa etanol, dan untuk Pertamax 92 dan Pertamax Turbo meningkatkan jarak tempuh sebesar masingmasing $153 \%$ dan $130 \%$ untuk kecepatan 40 $\mathrm{km} / \mathrm{j}$. Selengkapnya, peningkatan jarak tempuh dapat dilihat pada Tabel 10 dan Gambar 10.

Tabel 9 Konsumsi bahan bakar Pertamax Turbo dengan kandungan ethanol $0 \%, 8 \%$, $10 \%, 12 \%$ sepeda motor 125 cc dalam $\mathrm{km} / \mathrm{L}$

\begin{tabular}{crrrr}
\hline \multirow{2}{*}{$\mathbf{K e c}$} & \multicolumn{4}{c}{ Kandungan ethanol v/v } \\
\cline { 2 - 5 }$(\mathbf{k m} / \mathbf{j})$ & $\mathbf{0 \%}$ & $\mathbf{8 \%}$ & $\mathbf{1 0 \%}$ & $\mathbf{1 2 \%}$ \\
\hline 10 & 7.04 & 5.04 & 9.41 & 7.31 \\
20 & 13.78 & 9.74 & 22.36 & 14.94 \\
30 & 15.22 & 14.02 & 33.68 & 20.92 \\
40 & 18.91 & 18.81 & 43.53 & 26.76 \\
50 & 23.06 & 19.76 & 51.07 & 30.69 \\
\hline
\end{tabular}

Tabel 10 Peningkatan jarak tempuh untuk kandungan ethanol $10 \%$ dalam bensin menggunakan sepeda motor $125 \mathrm{cc}$, dalam \%

\begin{tabular}{ccccc}
$\begin{array}{c}(\mathbf{k m} / \mathbf{j} \\
)\end{array}$ & $\begin{array}{c}\text { Premiu } \\
\mathbf{m}\end{array}$ & $\begin{array}{c}\text { Pertalit } \\
\mathbf{e}\end{array}$ & $\begin{array}{c}\text { Pertama } \\
\mathbf{x ~ 9 2}\end{array}$ & $\begin{array}{c}\text { Pertama } \\
\text { x Turbo }\end{array}$ \\
\hline 10 & 243 & 134 & 110 & 34 \\
20 & 217 & 132 & 110 & 62 \\
30 & 172 & 113 & 145 & 121 \\
40 & 182 & 100 & 153 & 130 \\
50 & 170 & 136 & 147 & 121 \\
\hline
\end{tabular}

Peningkatan jarak tempuh sebagai akibat penambahan etanol bertentangan dengan hasil penelitian yang telah dilakukan oleh Barakat, et al. (2016), yang menguji konsumsi bahan bakar dengan variasi putaran mesin menunjukkan bahwa semakin besar kandungan ethanol semakin banyak bahan bakar yang digunakan. Namun demikian, hasil penelitian lain menunjukkan kandungan ethanol dalam bensin meningkatkan efisiensi (Stradling, et al. 2013), sedangkan pengujian menggunakan berbagai macam merek dan tipe mobil menunjukkan efek yang tidak menentu antara menurunkan efisiensi $15 \%$ sampai meningkatkan efisiensi $24 \%$ (Yan, et al. 2013).

Peningkatan jarak tempuh akibat kandungan etanol pada bensin produk PT Pertamina baru terlihat pada penggunaan sepeda motor $115 \mathrm{cc}$ dan $125 \mathrm{cc}$ untuk satu merek dan satu tipe tertentu saja. Penyebab peningkatan jarak tempuh karena desain mesin 


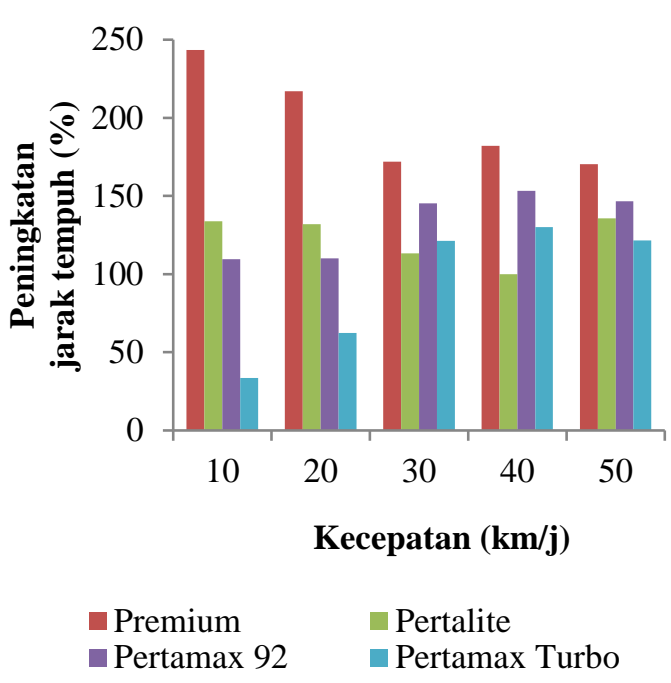

Gambar 10 Peningkatan jarak tempuh untuk kandungan ethanol $10 \%$ menggunakan sepeda motor $115 \mathrm{cc}$

sepeda motor yang sesuai dengan spesifikasi bahan bakar campuran bensin dan etanol. Namun demikian, penelitian lebih jauh dan mendalam perlu dilakukan untuk melihat efek kandungan etanol pada bensin yang digunakan di Indonesia terhadap konsumsi bahan bakar dan pengaruhnya terhadap mesin, mengingat etanol bersifat higroskopis.

\section{KESIMPULAN}

Kandungan etanol pada bensin meningkatkan jarak tempuh sepeda motor. Peningkatan tertinggi didapatkan pada kandungan etanol $10 \%$ untuk semua jenis bensin dibandingkan tanpa etanol

\section{DAFTAR PUSTAKA}

Barakat, Y., N.Awad, E., \& Ibrahim, V. (2016). Fuel consumption of gasoline ethanol blends at different engine rotational speeds. Egyptian Journal of Petroleum, 25 (3), 309-316.

Priangkoso, T., Wildana, A., \& Setyoko. (2016). Hubungan kecepatan, posisi gigi, dan jenis bahan bakar dengan konsumsi bahan bakar sepeda motor. Momentum, 10 (2), 37-41.

Saini, M. K., Garg, N., Singh, A. K., Tyagi, A. K., Niyogi, U. K., \& Khandal, R. K. (2010). Ethanol Blended Fuel in India: An Overview. Journal of Biofuels, 1 (2), 209219.

Stradling, R., Bellier, A., Barrio, M. D., Farenback-Brateman, J., Hovius, H., Jackson, A., et al. (2013). Assessment of the impact of ethanol content in gasoline on fuel consumption, including a literature review up to 2006. Brussel: Concawe.

Yan, X., Inderwildi, O. R., King, D. A., \& Boies, A. M. (2013). Effects of Ethanol on Vehicle Energy Efficiency and Implications on Ethanol Life-Cycle Greenhouse Gas Analysis. Environtmental Science \& Technology, 47 (11), 5535-5544. 